\title{
Case Report: Successful Sporozoite Challenge Model in Human Volunteers with Plasmodium vivax Strain Derived from Human Donors
}

\author{
Sócrates Herrera , Olga Fernández, María R. Manzano, Bermans Murrain, Juana Vergara, \\ Pedro Blanco, Ricardo Palacios, Juan D. Vélez, Judith E. Epstein, Mario Chen-Mok, Zarifah \\ H. Reed, and Myriam Arévalo-Herrera \\ Instituto de Inmunología, Universidad del Valle, Cali, Colombia; Centro Internacional de Vacunas, \\ Cali, Colombia; Departamento de Ciencias Agrícolas, Universidad Nacional de Colombia, \\ Palmira, Colombia; Division of Infectious Diseases, Federal University of Sao Paulo, Brazil; \\ Fundación Clínica Valle del Lili, Cali, Colombia; Family Health International, Durham, North \\ Carolina; Malaria Program, Naval Medical Research Center, Silver Spring, Maryland; Initiative for \\ Vaccine Research, World Health Organization, Geneva, Switzerland
}

\section{Abstract}

Successful establishment of a Plasmodium vivax sporozoite challenge model in humans is described. Eighteen healthy adult, malaria-naïve volunteers were randomly allocated to Groups A$\mathrm{C}$ and exposed to $3 \pm 1,6 \pm 1$, and $9 \pm 1$ bites of Anopheles albimanus mosquitoes infected with $P$. vivax, respectively. Seventeen volunteers developed signs and symptoms consistent with malaria, and geometric mean prepatent periods of 11.1 days (9.3-11) for Group A; 10.8 days (9.8-11.9) for Group B; and 10.6 days (8.7-12.4) for Group C, with no statistically significant difference among groups (Kruskal-Wallis, $P=0.70$ ). One volunteer exposed to eight mosquito bites did not develop a parasitemia. No differences in parasite density were observed and all individuals successfully recovered after anti-malarial treatment. None of the volunteers developed parasite relapses within an 18-month follow-up. In conclusion, malaria-naive volunteers can be safely and reproducibly

\footnotetext{
Copyright $(2009$ by The American Society of Tropical Medicine and Hygiene

*Address correspondence to Sócrates Herrera, Centro Internacional de Vacunas, AA 26020, Cali, Colombia. sherrera@inmuno.org. Reprint requests: Sócrates Herrera, Centro Internacional de Vacunas, AA 26020, Cali, Colombia, sherrera@inmuno.org. Authors' addresses: Sócrates Herrera, Olga Fernández, Bermans Murrain, Juana Vergara, Pedro Blanco, and Myriam Arévalo-Herrera, Instituto de Inmunología, Edificio de Microbiología, Facultad de Salud, Universidad del Valle, sede San Fernando, AA 25574, Tel: (572)-5581931, Fax: (572)-5570449 and Centro Internacional de Vacunas, AA 26020, Tel: (572)-5574929, Fax: (572)-5574921 ext. 102,Cali, Colombia, sherrera@inmuno.org,olgalufe@yahoo.com, bermansmurrain@yahoo.com, jvergara@inmuno.org, pblancot@gmail.com, and marevalo@inmuno.org. María R. Manzano, Departamento de Ciencias Agrícolas, Universidad Nacional, Tel: (57)-316-445-2253, Palmira, Colombia, mrmanzano@palmira.unal.edu.co. Ricardo Palacios, Division of Infectious Diseases, Federal University of Sao Paulo, Brazil, Rua Napoleao de Barros, 715, Sao Paulo, CEP 040024-002, Brazil, Tel: (55)-11-6452-4271, Fax: (55)-11-6463 2933, ricardopalacios@gmx.net. Juan D. Vélez, Fundación Clínica Valle del Lili, Cali, Colombia, AA 020338, Tel: (572)-3319090, jdvelez@telesat.com.co. Judith E. Epstein, US Military Malaria Vaccine Program, Naval Medical Research Center/ Walter Reed Army Institute of Research, Silver Spring, MD. Mario Chen-Mok, Family Health International, Durham, North Carolina, NC 27713, Tel: (919)-544-7040 ext. 11399, Fax: (919)-544-7261, mchen@ fhi.org. Zarifah H. Reed, Regional Emerging Diseases Intervention (REDI) Centre. 10 Biopolis Road \#02-01 Chromos, Singapore 138670, Tel: (65)-9839-8084, Fax: (65)-6874-7031, zareed@redi.org.sg.

Disclosure: Judith E. Epstein is a service member in the U.S. Navy. This work was prepared as part of her official duties. Title 17 U.S.C. $\$ 105$ provides that "Copyright protection under this title is not available for any work of the United States Government." Title 17 U.S.C. §101 defines a U.S. Government work as a work prepared by a military member or employee of the U.S. Government as part of that person's official duties.

Disclaimer: The views in this article are those of the authors and do not necessarily reflect the official policy or position of the U.S. Department of the Navy, U.S. Department of Defense, or the U.S. Government.
} 
infected with bites of 2-10 An. albimanus mosquitoes carrying $P$. vivax sporozoites. This challenge method is suitable for vaccine and anti-malarial drug testing.

\section{INTRODUCTION}

An estimated 80 million cases of Plasmodium vivax malaria occur annually worldwide ${ }^{1}$ and failure of classic malaria control measures has prompted the search for a malaria vaccine. Progress has been achieved in the development of $P$. vivax pre-erythrocytic subunit vaccines such as the circumsporozoite (CS) and thrombospondin-related adhesion proteins (TRAP) ${ }^{2}$ and vaccines based on asexual blood stage antigens such as the merozoite surface protein-1 (MSP-1) and the Duffy-binding protein (DBP).3,4 Several preclinical trials using both synthetic peptides and recombinant proteins representing these and other antigens have been carried out in non-human primates. 2 Additionally, results from Phase 1 clinical trials conducted with different formulations of $P$. vivax CS-derived subunit vaccines indicate that these vaccines are safe and immunogenic. ${ }^{4,5}$

Evaluation of the safety and efficacy of pre-erythrocytic and possibly also erythrocytic stage malaria vaccines is greatly facilitated by a safe, reliable, and reproducible method of infecting human volunteers. With the development of continuous $P$. falciparum cultures, ${ }^{6}$ a successful model of infection with this species through mosquito bites was developed two decades ago, ${ }^{7}$ which in turn led to progress in the development of RTS,S/AS02A, a vaccine based on the $P$. falciparum CS protein, ${ }^{8-10}$ and other vaccine candidates. ${ }^{11}$ Experimental human sporozoite challenge has also contributed to systematically assessing the efficacy of $P$. falciparum irradiated sporozoite vaccines in malaria-naïve volunteers and to propose its development as a cryopreserved, non-replicating vaccine against malaria. ${ }^{12,13}$

At present, without long-term in vitro cultures for $P$. vivax, an experimental sporozoite challenge model would require parasites derived from the blood of $P$. vivax-infected patients. The main objective of this study was to develop a reproducible $P$. vivax sporozoite challenge model that is urgently needed for assessing the protective efficacy of $P$. vivax subunit or attenuated parasite vaccines. Herein, we report findings on the development of a $P$. vivax sporozoite challenge model in malaria-naïve volunteers exposed to bites of Anopheles mosquitoes infected by blood from infected patients.

\section{MATERIALS AND METHODS}

\section{Study participants}

Eighteen healthy malaria-naïve subjects (19-45 years of age) participated as challenge volunteers, and 15 P. vivax-infected patients served as parasite donors. All participants were recruited after the protocol was approved by the Ethics Committee of the Universidad del Valle, the Fundación Clínica Valle del Lili, and Springfield Committee Research Involving Human Subjects (SCRIHS) appointed by the World Health Organization (WHO). The trial complied with the International Conference on Harmonization (ICH) E-6 Guidelines for Good Clinical Practices.

During recruitment, potential risks of participation were explained, including exposure to potential unknown pathogens harbored by Anopheles mosquitoes and to $P$. vivax parasites. Similarly, the potential symptoms associated with malarial infection and to anti-malarial therapy were explained. Study participants were provided ample opportunity to read the consent forms, to ask questions of the study investigators, and to consult with family and friends. Separate written informed consents were obtained from each volunteer for enrollment and for human immunodeficiency virus (HIV) screening. Participants were 
allowed to withdraw voluntarily from the study at any time. Individuals were excluded from the study if they had conditions that would increase the risk of an adverse outcome or abnormal laboratory test values (Table 1).

\section{Study design}

A randomized, open-label clinical trial was designed to standardize a $P$. vivax sporozoite challenge model in malaria-naïve volunteers, specifically, the relationship between the number of infectious mosquito bites and the likelihood of developing patent parasitemia detectable by Giemsa-stained thick blood smear (TBS). The study was divided into two steps. Step A was designed to produce mature $P$. vivax sporozoites suitable for inoculation into humans; and Step B was designed to assess the safety and reproducibility of the sporozoite challenge. For Step A, patients with infective $P$. vivax gametocytes detected by TBS were recruited from the outpatient clinics at the Immunology Institute (IDIV) in Cali and Buenaventura, Colombia. Patients donated $35 \mathrm{~mL}$ of whole blood, which was screened for co-infections that could potentially represent a threat to the health of volunteers. The blood was then artificially fed to Anopheles mosquitoes. ${ }^{14}$ For Step B, malaria-naive subjects were exposed to the bites of $3 \pm 1,6 \pm 1$, or $9 \pm 1$ infected mosquitoes to determine the prepatent period of the infection and its reproducibility.

\section{Blood donation and blood quality assurance}

The EDTA vacutainer tubes (Becton Dickinson, Franklin Lakes, NJ) were used to collect 35 $\mathrm{mL}$ of whole blood from each infected patient, which were divided into two aliquots: a 15 $\mathrm{mL}$ sample for mosquito feeding and a $20 \mathrm{~mL}$ sample that was transported to the blood bank of the Valle del Lili Clinic for routine screening for a panel of common infectious agents (viral, bacterial, parasitic), including confirmation of Plasmodium species ( $P$. vivax, $P$. falciparum, $P$. malariae) by polymerase chain reaction (PCR) (Table 2). ${ }^{15}$ The rationale behind the blood screening and direct mosquito feeding on human volunteers was based on two premises: 1) standard blood bank screening is universally accepted as a safety procedure that ensures that no pathogens are transmitted from human-to-human during a blood transfusion. Therefore, blood samples determined to be negative for pathogens other than $P$. vivax by standard blood bank screening should be safe enough to be transferred from human-to-human through a mosquito bite. 2) Anopheles mosquitoes have not been reported to trans mit any pathogen other than Plasmodium. Before the study, we carried out an extensive bibliographic search and consulted with U.S. and Colombian experts on virology, parasitology, and ento mology about potential pathogens that might be trans mitted by Anopheles and could represent a threat for the volunteers exposed to challenge. There was a consensus that as yet no other pathogen had been reported to be transmitted by Anopheles mosquitoes, including those comprised in the blood bank screening. However, mosquitoes were discarded using a biosafety procedure if after feeding blood was confirmed to have any co-infection.

\section{Mosquito infection}

Anopheles albimanus mosquitoes Buenaventura strain, have been reared under laboratory conditions at IDIV in Cali for about 10 years. This mosquito colony has been successfully used to regularly produce sporozoites ${ }^{14,16}$ and for studies on malaria transmission-blocking immunity. ${ }^{17}$ Here, mosquitoes were fed within $2-3$ hours after the $P$. vivax-infected blood (gametocytemia $\geq 0.1 \%$ ) was collected in Buenaventura. The $15 \mathrm{~mL}$ blood was centrifuged at $500 \times g$ for 5 minutes at room temperature, plasma was removed, and cells were washed once with RPMI 1640 medium (Gibco Cell Culture Systems, Invitrogen, Grand Island, NY ). Parasitized erythrocytes were reconstituted to $50 \%$ hematocrit with pooled human AB non-immune, complement-inactivated serum obtained from the Red Cross blood bank and were used to infect lots of 4,000 female mosquitoes (3-4 days old) using a water-jacketed 
membrane apparatus at $37^{\circ} \mathrm{C}$, described previously. 14 Infected mosquitoes were maintained under strict biosafety conditions at $27 \pm 1{ }^{\circ} \mathrm{C}$ and relative humidity of $82 \%$ and a sugar solution supplemented with $0.05 \%$ para-aminobenzoic-acid was provided.18 Samples of fed mosquitoes were dissected and microscopically examined 7-8 days after the blood meal to determine the presence of oocysts in the midgut, and on Days 14 and 15 to assess the presence of sporozoites in salivary glands.19 Mosquito infections were graded as $1+(1-10$ spz), 2+ (11-100 spz), 3+ (101-1000 spz), and 4+ (> $1001 \mathrm{spz}) .7$

\section{Sporozoite challenge}

The proposed infective biting dose was to be 3,6, and 9 mosquitoes, respectively. However, a range of plus or minus one bite per dose was allowed. Therefore, screen-meshed boxes ( 7 $\times 7 \times 7 \mathrm{~cm}$ ) were filled with 4,7 , and 10 mosquitoes, to have a better chance of achieving the targeted mosquito dose in a single biting round. Participants who did not complete the minimal targeted dose were subjected to a second round of biting. Eighteen malaria-naïve volunteers were randomly assigned to one of three groups $(N=6)$ and were exposed by group, from the fewest ( 3 bites) to the greatest (9 bites) number of bites. Sporozoite challenge was carried out under strict adherence to experimental protocol in a secure room in the entomology unit at the IDIV. Volunteers were asked not to use any topical chemicals (e.g., soap, deodorant, perfume) that could affect mosquito feeding. Mosquitoes were allowed to bite the flexor side of the forearm for a 10 to 15 -minute period, previously determined to be sufficient for full An. albimanus engorgement. After biting, all mosquitoes were dissected to confirm the presence of blood meal and sporozoites. Mosquitoes were considered positive if any number of sporozoites $(>1)$ was detected microscopically. Study participants were observed for 1 hour at the entomology unit, followed up by phone 8 hours later, and examined again 24 hours thereafter to assess the response to challenge.

\section{Malaria diagnosis and patient follow-up}

From Day 7 post-challenge onward, volunteers had daily follow-up visits during which symptoms and signs of malaria were assessed and blood was collected for TBS and Plasmodium PCR (the latter performed retrospectively).

The TBS were performed using $50 \mu \mathrm{L}$ of whole blood collected by finger prick that were spread over a rectangular area of approximately $1.5 \mathrm{sq} \mathrm{cm}$ and were stained with freshly prepared $10 \%$ Giemsa stain. ${ }^{20} \mathrm{~A}$ total of 300 microscopic fields were examined before a slide was considered negative. When TBS were found positive, parasitemia was quantified by estimating the number of parasites counted in presence of 300 leukocytes and calculating absolute parasitemia according the leukocyte counts per $\mu \mathrm{L}$. Smears were read by experienced microscropists and a random sample of TBS was subjected to quality control by a microscopist from the malaria control program.

Participants were treated with anti-malarial drugs as soon as parasites were detected by TBS. Treatment consisted of chloroquine $(1,500 \mathrm{mg}$ chloroquine base provided orally in divided doses: $600 \mathrm{mg}$ initially followed by $450 \mathrm{mg}$ given 24 and 48 hours later) and primaquine (two $15 \mathrm{mg}$ doses given once per day for 14 days). Volunteers were provided with intravenous fluids, analgesics, and antiemetics as needed. Signs and symptoms consistent with malaria were assessed by clinical examination and were graded $1-5$ according to their severity following the National Cancer Institiute (NCI) criteria for adverse events (CTCAE ) as follows: Grade $1=$ Low, Grade $2=$ Moderate, Grade $3=$ Severe, Grade $4=$ Serious, and Grade $5=$ Death. Pruritus was graded from 1 to $3(1=$ mild or localized; $2=$ intense or widespread; and $3=$ intense or widespread and interfering with activities of daily living). Because there is no common terminology AE agreement, for edema and erythema following mosquito bites, an adaptation from the CTCAE v 3 for "injection site/extravasation changes" 
was used as follows: Grade $1=$ local pain/edema and erythema; Grade $2=$ pain or swelling with inflammation or phlebitis; Grade $3=$ ulceration or necrosis. Pain was scored as Grade 1 $=$ mild not interfering with function; Grade $2=$ moderate pain (pain or analgesics interfering with function, but not interfering with activities of daily living); Grade $3=$ severe pain (pain or analgesics severely interfering with activities of daily living).

\section{Clinical laboratory tests}

Clinical laboratory screening in -cluding an electrocardiogram confirmed the health status of volunteers 1 month before challenge and after the study was completed (Table 1). Any abnormality found in the electrocardiogram was considered as an exclusion criterion. Tests for hemoglobin, white blood cell count, platelet count, and total bilirubin were performed again on Days 11 and 53 post-challenge.

\section{Statistical methods}

Sample size ( $N=6$ per group) was based on the minimum number of individuals that would be allowed to observe the occurrence of rarer events (e.g., events that occur in approximately 5\% of individuals) with reasonable probability based on a binomial assumption. The overall sample size of 18 would be sufficient to detect even rare events. A titration of mosquito bites (biting doses) was established; beginning with that arbitrarily considered the minimum number required causing an infection. Prepatent periods and duration of symptoms were expressed as geometric means. Differences among the groups were estimated by the Kruskal-Wallis test, and were considered statistically significant at $P$ values less than 0.05 .

\section{RESULTS}

\section{Study population}

Eighteen volunteers (9 men, 9 women) that received sporozoite challenge had a mean age of 27 years and were randomly assigned to three groups of six volunteers ( 3 men and 3 women per group) with no differences in age between the groups (Kruskal-Wallis, $P=0.70$ ) (Table 4). The $15 P$. vivax-infected donors (11 men, 4 women) had a mean age of 30 years.

\section{Mosquito infection}

The 15 patients provided written informed consent and served as donors of infected blood. Whole blood samples were examined using standard blood bank screening for co-infections; of those a total of four presented co-infections such as P. falciparum, Hepatitis B, and Hepatitis $\mathrm{C}$ and were discarded (Table 3). Blood used for mosquito feeding had parasite densities ranging from $80-8,720$ (mean 3,693) $P$. vivax asexual erythrocytic stage parasites/ $\mu \mathrm{L}$ and gametocytemia ranging from $40-3,360$ (mean 934) parasites $/ \mu \mathrm{L}$.

Four mosquito lots were discarded because of co-infection in blood used for feeding. One parasite donor had a mixed $P$. vivax/P. falciparum infection and three blood samples carried the hepatitis B or hepatitis C virus; patients were treated and referred for medical follow-up. Six of the remaining 11 lots of mosquitoes showed infections with $>50 \%$ of the mosquitoes having sporozoites in salivary glands, whereas the other five were considered ineligible for challenge because of low percentage $(<50 \%)$ of sporozoite-infected mosquitoes. On the day before challenge, two mosquito lots examined microscopically showed sporozoite rates of $97 \%$ and $86 \%$, respectively. The $97 \%$ lot $(3+$ sporozoite score in salivary glands) was selected for use. 


\section{Sporozoite challenge}

Sixteen volunteers were exposed to infection during the first day and the other two (from Group C), were challenged on Day 2. The number of mosquitoes required to complete the biting dose and the number of cycles required for each dose is indicated in Table 4. Some individuals developed minor, transient discomfort that was not associated with the number of bites. Local pruritus was observed most frequently in Group B (four of six volunteers) but disappeared within 2 days. One volunteer from Group $\mathrm{C}$ developed mild arm pain and localized pruritus that lasted for 5 days (Table 5).

\section{Prepatent period and clinical follow-up}

Seventeen volunteers developed malaria as confirmed by TBS and PCR, and one volunteer subjected to eight mosquito bites was determined negative for malaria in a total of 20 thick smears and 15 PCR performed during the 30-day follow-up period. We believe that this volunteer who was a paramedic, surreptitiously used anti-malarials; however, as serum levels of anti-malarial drugs were not measured, we are not able to make an unequivocal confirmation. The latter (volunteer no. 213) was given anti-malarial treatment on Day 30 and was followed up as per protocol (Table 4). Patent parasitemia was confirmed between 9 and 13 days (geometric mean $11 \pm 2$ days) after the mosquito bites without any correlation between the challenge dose and the prepatent periods, which were 11.1 days, confidence interval (CI) 95\% (9.3-11), for Group A; 10.8 days, CI 95\% (9.8-11.9), for Group B; and 10.6 days, CI 95\% (8.7-12.4), for Group C. No statistically significant difference was observed in the prepatent period of the different groups (Kruskal-Wallis $P=0.70$ ) (Table 1). In five cases, parasites were detected earlier by PCR than by TBS, whereas in 11 cases both methods were equally sensitive. In one case, parasites were detected earlier by TBS than by PCR. Parasitemia ranged from 75 to 420 parasites/ $\mu \mathrm{L}$ (Table 4).

All 17 infected-volunteers started to develop signs and symptoms consistent with malaria on Day 9 post-challenge, but some of the clinical manifestations appeared only 4 to 5 days later. The most frequent were chills, fever, headache, arthralgia, myalgia, and malaise followed by weakness and nausea (Table 6). Fever (axillary temperature $>38^{\circ} \mathrm{C}$ ) was documented in 10 of the volunteers and six more reported having had fever without confirmation. All individuals cleared parasitemia between 24 and 48 hours after initiating anti-malarial treatment, and all successfully recovered within 2 to 3 days without any severe or serious adverse events (Table 6). No parasites including gametocytes were observed after treatment. The most frequent symptoms associated with treatment were epigastralgia with duration of 1 to 21 days; nausea, 1-5 days; and vomiting, 1-3 days.

In addition, five patients developed blurred vision that lasted for 2 to 3 days after treatment initiation (Table 6). None of the volunteers required hospitalization, but because of nausea and vomiting, seven required fluid therapy that was administered at the MVDC outpatient clinic. The volunteer who did not become infected was treated with the anti-malarial protocol after a month of follow-up.

\section{Clinical laboratory follow-up}

Hematologic tests indicated that except for one individual that had a moderately decreased hemoglobin $(\mathrm{Hb})$ level on Day $11(\mathrm{Hb}=10.3 \mathrm{~g} / \mathrm{dL})$, all volunteers maintained normal $\mathrm{Hb}$ levels throughout the study. Eight volunteers developed mild leucopenia $(2,100-4,000$ white blood cell $[\mathrm{WBC}] / \mu \mathrm{L}$ ) on Day 12 post-challenge, and three had platelet counts below $150,000 / \mu \mathrm{L}$, with the lowest being $96,000 / \mu \mathrm{L}$. Only one of the individuals (no. 226) had a decrease in all three hematologic parameters. All abnormal hematologic values rapidly returned to normal after treatment. Four individuals had abnormal alanine aminotransferase (ALT) on Day 12 and two of them maintained mildly increased levels on Day 53. Except for 
two individuals that had slightly high levels of blood urea nitrogen (BUN) on Day 53, BUN values remained normal in all volunteers throughout the study. BUN values in these two participants returned to normal levels at follow-up visit 1 month later.

\section{DISCUSSION}

We showed that malaria-naive volunteers can be safely and reproducibly infected by bites of An. albimanus mosquitoes carrying $P$. vivax sporozoites. Although prepatent periods in the 17 infected volunteers varied between 9 and 13 days, all developed malaria symptoms at Day 9 post-challenge. Fever was not as frequent as expected and it was not an early symptom. Over half of the individuals presented with their first febrile episode after Day 10. Malaise, arthralgia, myalgias, and headache occurred more frequently and appeared earlier than fever.

Prepatent periods (geometric mean, range 9.3-11) were similar to those reported for $P$. vivax in a previous study. ${ }^{21} \mathrm{We}$ were, however, surprised that there was no association between the number of mosquito bites and the length of the prepatent period. In previous studies conducted with $P$. falciparum, an inverse correlation between the number of infectious bites and the prepatent period was reported. ${ }^{22,23}$ Nevertheless, in a recent study by Verhage and others, ${ }^{24}$ only a weak inverse relationship between the number of $P$. falciparum-infected mosquito bites (1-2 bites versus 4-7 bites) and the prepatent period was found. Of note, all the volunteers were exposed only to one mosquito lot infected from a single donor. It is feasible that the prepatent period, and other pathogenic features, might rely more on the infectious strain than on the amount of inoculated parasites. Challenges including mosquito lots infected from several donors might result in more variable prepatent periods.

As expected, because of prompt diagnosis, there was no great difference in parasite density (75-420 parasites $/ \mu \mathrm{L}$ ) between the groups, and no relationship between parasitemia and malaria symptoms was observed. Interestingly, parasitemia was cleared in most cases (13/17) within the first 24 hours of treatment and the remainder cleared within 2 days. The fact that parasitemia, including gametocytemia, was not observed after anti-malarial treatment, provides confidence on the efficacy of the treatment particularly to prevent any further malaria spreading through the infected volunteers. Furthermore, the study site (Cali) is not endemic for malaria transmission because of the absence of local malaria vectors. Even though all volunteers presented with symptoms beginning at Day 9 post-challenge, prepatent periods were variable. The narrow prepatent window observed in this study would be suitable for vaccine testing as it would allow the use of smaller experimental groups to determine differences between controls and immunized volunteers. This model would allow assessment of whether vaccinated individuals become completely immune (no parasitemia) or develop partial protection (prolonged prepatent periods).

In conclusion, the challenge system used in our study was found to be safe and to result in only mild to moderate clinical signs and symptoms, which resolved quickly without complications. Careful volunteer selection and follow-up is advisable to avoid spreading of the infection after travel to areas with capable vectors, and to provide timely therapy in case of relapses. Most laboratory abnormalities were mild and resolved after treatment.

Because there is as yet no system to cryopreserve $P$. vivax gametocytes for further mosquito infection, new trials may be required to conclusively determine the reproducibility of this method with different wild Plasmodium isolates. For this purpose, we plan to conduct a new challenge trial using different $P$. vivax isolates at the lowest dose (2-4) that proved to induce reproducible infections. To ascertain the reproducibility of infection in all exposed volunteers, it would be advisable to consider the determination of anti-malarial consumption 
in challenged volunteers. Furthermore, to address the variability that is likely to result from the fact that every challenge will have a different donor strain, we plan to establish a bank of parasite isolates for further genotyping. The availability of this $P$. vivax challenge model, in conjunction with new methodologies such as transcriptome analysis of infected individual volunteers, should facilitate a better understanding of the natural history of $P$. vivax infection. ${ }^{25,26}$ Most importantly, the development of this model is an essential step in the critical path to effective vaccines and anti-malarial drugs against $P$. vivax infections.

\section{Acknowledgments}

The investigators express their sincere gratitude to the volunteers who participated in this study. We also thank the Fundación Clínica Valle del Lili (FCVL) for the services of their blood bank and emergency room. We wish to give special acknowledgment to the team at MVDC that supported the work for this study, particularly A. C. Londoño, F. Zamora, L. Acuna, A. Jordan, A. Rincon, and F. Yasnot.

Financial support: This work was supported by World Health Organization Initiative for Vaccine Research (grant no. LA35735G), National Institute of Allergy and Infectious Diseases (NIAID grant no. AI49486-05/TMRC), Colombian National Research Council, COLCIENCIAS, and the Malaria Vaccine and Drug Development Center Foundation. The contribution of U.S. Navy staff was supported by Work Unit Number 6000.RAD1.F.A309.

\section{REFERENCES}

1. Mendis K, Sina BJ, Marchesini P, Carter R. The neglected burden of Plasmodium vivax malaria. Am J Trop Med Hyg 2001;64:97-106. [PubMed: 11425182]

2. Arévalo-Herrera M, Herrera S. Plasmodium vivax malaria vaccine development. Mol Immunol 2001;38:443-455. [PubMed: 11741694]

3. Valderrama-Aguirre A, Quintero G, Gomez A, Castellanos A, Perez Y, Méndez F, Arévalo-Herrera M, Herrera S. Antigenicity, immunogenicity, and protective efficacy of Plasmodium vivax MSP1 PV2001: a potential malaria vaccine subunit. Am J Trop Med Hyg 2005;73:16-24. [PubMed: 16291762]

4. Arévalo-Herrera M, Castellanos A, Yazdani SS, Shakri AR, Chitnis CE, Dominik R, Herrera S. Immunogenicity and protective efficacy of recombinant vaccine based on the receptor-binding domain of the Plasmodium vivax Duffy binding protein in Aotus monkeys. Am J Trop Med Hyg 2005;73:25-31. [PubMed: 16291763]

5. Herrera S, Bonelo A, Perlaza BL, Fernandez OL, Victoria L, Lenis AM, Soto L, Hurtado H, Acuna LM, Velez JD, Palacios R, Chen-Mok M, Corradin G, Arévalo-Herrera M. Safety and elicitation of humoral and cellular responses in colombian malaria-naive volunteers by a Plasmodium vivax circumsporozoite protein-derived synthetic vaccine. Am J Trop Med Hyg 2005;73:3-9. [PubMed: 16291760]

6. Trager W, Jensen JB. Human malaria parasites in continuous culture. Science 1976;193:673-675. [PubMed: 781840]

7. Chulay JD, Schneider I, Cosgriff TM, Hoffman SL, Ballou WR, Quakyi IA, Carter R, Trosper JH, Hockmeyer WT. Malaria transmitted to humans by mosquitoes infected from cultured Plasmodium falciparum. Am J Trop Med Hyg 1986;35:66-68. [PubMed: 3511753]

8. Stoute JA, Slaoui M, Heppner DG, Momin P, Kester KE, Desmons P, Wellde BT, Garcon N, Krzych U, Marchand M. A preliminary evaluation of a recombinant circumsporozoite protein vaccine against Plasmodium falciparum malaria. RTS,S Malaria Vaccine Evaluation Group. N Engl J Med 1997;336:86-91. [PubMed: 8988885]

9. Heppner DG Jr, Kester KE, Ockenhouse CF, Tornieporth N, Ofori O, Lyon JA, Stewart VA, Dubois P, Lanar DE, Krzych U, Moris P, Angov E, Cummings JF, Leach A, Hall BT, Dutta S, Schwenk R, Hillier C, Barbosa A, Ware LA, Nair L, Darko CA, Withers MR, Ogutu B, Polhemus ME, Fukuda M, Pichyangkul S, Gettyacamin M, Diggs C, Soisson L, Milman J, Dubois MC, Garcon N, Tucker K, Wittes J, Plowe CV, Thera MA, Duombo OK, Pau MG, Goudsmit J, Ballou WR, Cohen J. Towards an RTS,S-based, multi-stage, multi-antigen vaccine against falciparum malaria: progress at the Walter Reed Army Institute of Research. Vaccine 2005;23:2243-2250. [PubMed: 15755604] 
10. Bejon P, Lusingu J, Olotu A, Leach A, Lievens M, Vekemans J, Mshamu S, Lang T, Gould J, Dubois MC, Demoitie MA, Stallaert JF, Vansadia P, Carter T, Njuguna P, Awuondo KO, Malabeja A, Abdul O, Gesase S, Mturi N, Drakeley CJ, Savarese B, Villafana T, Ballou WR, Cohen J, Riley EM, Lemnge MM, Marsh K, von Seidlein L. Efficacy of RTS,S/AS01E vaccine against malaria in children 5 to 17 months of age. N Engl J Med 2008;359:2521-2532. [PubMed: 19064627]

11. Webster DP, Dunachie S, Vuola JM, Berthoud T, Keating S, Laidlaw SM, McConkey SJ, Poulton I, Andrews L, Andersen RF, Bejon P, Butcher G, Sinden R, Skinner MA, Gilbert SC, Hill AV. Enhanced $\mathrm{T}$ cell-mediated protection against malaria in human challenges by using the recombinant poxviruses FP9 and modified vaccinia virus Ankara. Proc Natl Acad Sci USA 2005;102:4836-4841. [PubMed: 15781866]

12. Hoffman SL, Goh LM, Luke TC, Schneider I, Le TP, Doolan DL, Sacci J, de la Vega P, Dowler M, Paul C, Gordon DM, Stoute JA, Church LW, Sedegah M, Heppner DG, Ballou WR, Richie TL. Protection of humans against malaria by immunization with radiation-attenuated Plasmodium falciparum sporozoites. J Infect Dis 2002;185:1155-1164. [PubMed: 11930326]

13. James ER, Lee K, Loyevsky M, Richman A, Li T, Chakravarty S, Gunesekera A, Chattopadhayay R, Ahumada A, Li M, Stafford R, Billingsley P, Hoffman SL. A cryopreserved metabolicallyactive non-replicating vaccine against malaria. Cryobiology 2008;57:317.

14. Hurtado S, Salas ML, Romero JF, Zapata JC, Ortiz H, Arévalo-Herrera M, Herrera S. Regular production of infective sporozoites of Plasmodium falciparum and $P$. vivax in laboratory-bred Anopheles albimanus. Ann Trop Med Parasitol 1997;91:49-60. [PubMed: 9093429]

15. Snounou G, Viriyakosol S, Jarra W, Thaithong S, Brown KN. Identification of the four human malaria parasite species in field samples by the polymerase chain reaction and detection of a high prevalence of mixed infections. Mol Biochem Parasitol 1993;58:283-292. [PubMed: 8479452]

16. Salas ML, Romero JF, Solarte Y, Olano V, Herrera MA, Herrera S. Development of sporogonic cycle of Plasmodium vivax in experimentally infected Anopheles albimanus mosquitoes. Mem Inst Oswaldo Cruz 1994;89(Suppl 2):115-119. [PubMed: 7565121]

17. Arévalo-Herrera M, Solarte Y, Yasnot MF, Castellanos A, Rincon A, Saul A, Mu J, Long C, Miller L, Herrera S. Induction of transmission-blocking immunity in Aotus monkeys by vaccination with a Plasmodium vivax clinical grade PVS25 recombinant protein. Am J Trop Med Hyg 2005;73:3237.

18. Peters W, Ellis D, Boulard Y, Landau I. The chemotherapy of rodent malaria XXXVI. Part IV. The activity of a new 8-aminoquinoline, WR 225,448 against exo-erythrocytic schizonts of Plasmodium yoelii yoelii. Ann Trop Med Parasitol 1984;78:467-478. [PubMed: 6524991]

19. Gamage-Mendis AC, Rajakaruna J, Weerasinghe S, Mendis C, Carter R, Mendis KN. Infectivity of Plasmodium vivax and P. falciparum to Anopheles tessellatus; relationship between oocyst and sporozoite development. Trans R Soc Trop Med Hyg 1993;87:3-6. [PubMed: 8465388]

20. Hanscheid T. Diagnosis of malaria: a review of alternatives to conventional microscopy. Clin Lab Haematol 1999;21:235-245. [PubMed: 10583325]

21. Garmham, P. Clinical Manifestations of Plasmodium falciparum Malaria Experimentally Induced by Mosquito Challenge. Academic Press; New York: 1980.

22. Church LW, Le TP, Bryan JP, Gordon DM, Edelman R, Fries L, Davis JR, Herrington DA, Clyde DF, Shmuklarsky MJ, Schneider I, McGovern TW, Chulay JD, Ballou WR, Hoffman SL. Clinical manifestations of Plasmodium falciparum malaria experimentally induced by mosquito challenge. J Infect Dis 1997;175:915-920. [PubMed: 9086149]

23. Powell RD, McNamara JV. Infection with chloroquine-resistant Plasmodium falciparum in man: prepatent periods, incubation periods, and relationships between parasitemia and the onset of fever in nonimmune persons. Ann NY Acad Sci 1970;174:1027-1041. [PubMed: 4993529]

24. Verhage DF, Telgt DS, Bousema JT, Hermsen CC, van Gemert GJ, van der Meer JW, Sauerwein RW. Clinical outcome of experimental human malaria induced by Plasmodium falciparuminfected mosquitoes. Neth J Med 2005;63:52-58. [PubMed: 15768480]

25. Ylostalo J, Randall AC, Myers TA, Metzger M, Krogstad DJ, Cogswell FB. Transcriptome profiles of host gene expression in a monkey model of human malaria. J Infect Dis 2005;191:400-409. [PubMed: 15633100] 
26. Schaecher K, Kumar S, Yadava A, Vahey M, Ockenhouse CF. Genome-wide expression profiling in malaria infection reveals transcriptional changes associated with lethal and nonlethal outcomes. Infect Immun 2005;73:6091-6100. [PubMed: 16113330] 


\section{Table 1}

Study participant requirements

\begin{tabular}{|c|c|}
\hline Exclusion criteria ${ }^{*}$ & Clinical laboratory test \\
\hline Hepatitis B or Hepatitis C virus infections & Hematologic \\
\hline HIV/AIDS infection & $\begin{array}{l}\text { CBC, reticulocyte count, G-6-PD determination, Duffy phenotype, ABO } \\
\text { and Rh group typing, hemoglobin electrophoresis and erythrocyte } \\
\text { sedimentation rates and } \mathrm{APTT}^{\dagger}\end{array}$ \\
\hline \multicolumn{2}{|l|}{ Cardiovascular disease } \\
\hline Hepatic or renal abnormalities & Cardiovascular function \\
\hline Immunodeficiency & Electrocardiogram \\
\hline \multirow[t]{2}{*}{ Autoimmune diseases } & Renal function \\
\hline & Urinalysis, Creatinine, Urea and $\mathrm{BUN}^{\dagger}$ \\
\hline Allergies & Hepatic function \\
\hline \multicolumn{2}{|l|}{ Duffy negative phenotype } \\
\hline & ALT, AST, Bilirrubin, LDH, Alkaline phosphatase, Total protein and $\mathrm{PT}^{\S}$ \\
\hline \multicolumn{2}{|l|}{ Previous malaria exposure $\left(\mathrm{IFAT}^{\S}>1: 100\right)$} \\
\hline & Blood chemistry \\
\hline Residence in a malaria-endemic area & Glucose, $\mathrm{C}$ reactive protein and ANA \\
\hline \multirow[t]{2}{*}{ Previuos participation in experimental malaria vaccination } & Infectious diseases \\
\hline & HIV, HBC, HCV, HTLV-1 and -2, RPR for syphilis and Chagas disease \\
\hline \multicolumn{2}{|l|}{$\begin{array}{l}\text { Pregnancy, breast feeding or plans to become pregnant during } \\
\text { the study }\end{array}$} \\
\hline & Pregnancy testing \\
\hline Plans to have surgery & $\beta$-HCG in serum \\
\hline
\end{tabular}


Table 2

Microbial agents included in the blood bank screening for parasite donors*

\begin{tabular}{|c|c|c|c|c|}
\hline Disease & Pathogen & Technique & Reference values & Commercial brand \\
\hline Malaria & P. falciparum/P. vivax & PCR & Positive or Negative & Experimental \\
\hline Hepatitis B & $\mathrm{HB}$ virus & MEIA for HBsAg Abs & $\mathrm{OD} \geq 2.0$ & ABBOTT \\
\hline Hepatitis C & HCV-3 Antibodies & MEIA for HCV-3 Abs & $\mathrm{OD} \geq 1.0$ & ABBOTT \\
\hline Syphilis & Treponema pallidum & $\begin{array}{l}\text { Flocculation of reagins and cardiolysins coated coal } \\
\text { particles }\end{array}$ & Dark aggregates & Biomerieux \\
\hline PET & HTLV I/HTLV II & MicroELISA for gp46-I, p21-I, gp46-II & $>$ Cutoff & ABBOTT \\
\hline CHAGAS & Trypanosoma cruzi & MicroELISA for T.cruzi rec proteins & $>$ Cutoff & IMMCO \\
\hline
\end{tabular}

* All tests have external periodical QC by the College of American Pathologist, The Medical Laboratory Evaluation, and the Colombian regulatory agency INVIMA. 


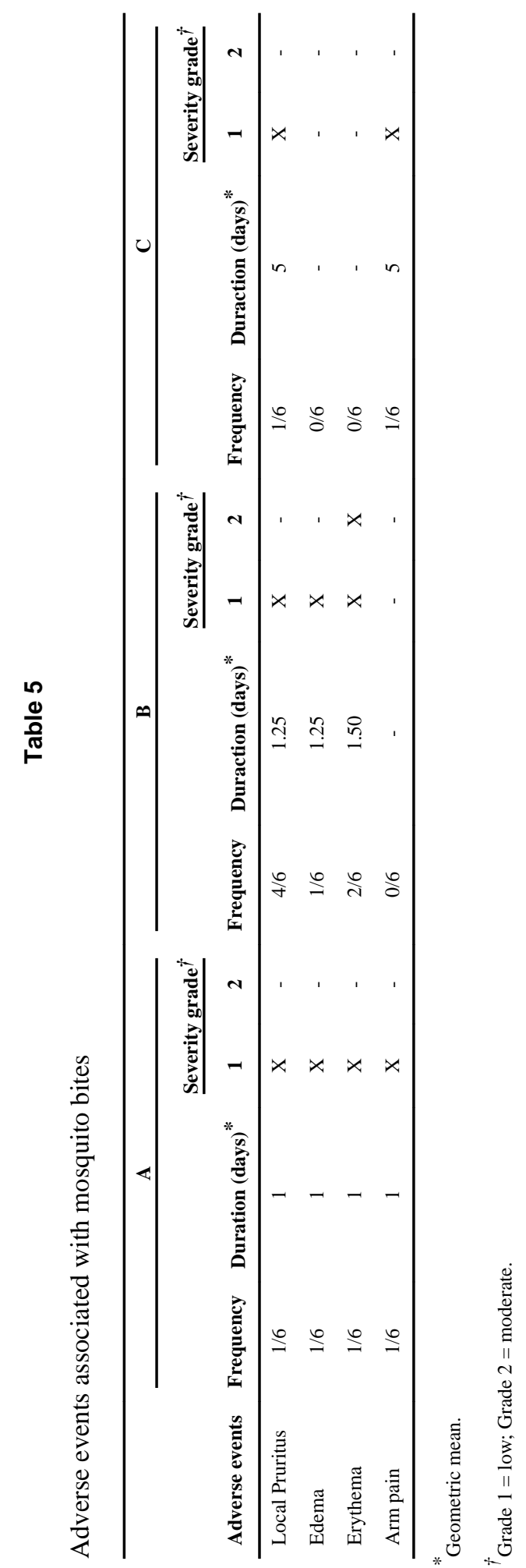

Am J Trop Med Hyg. Author manuscript; available in PMC 2010 November 1. 


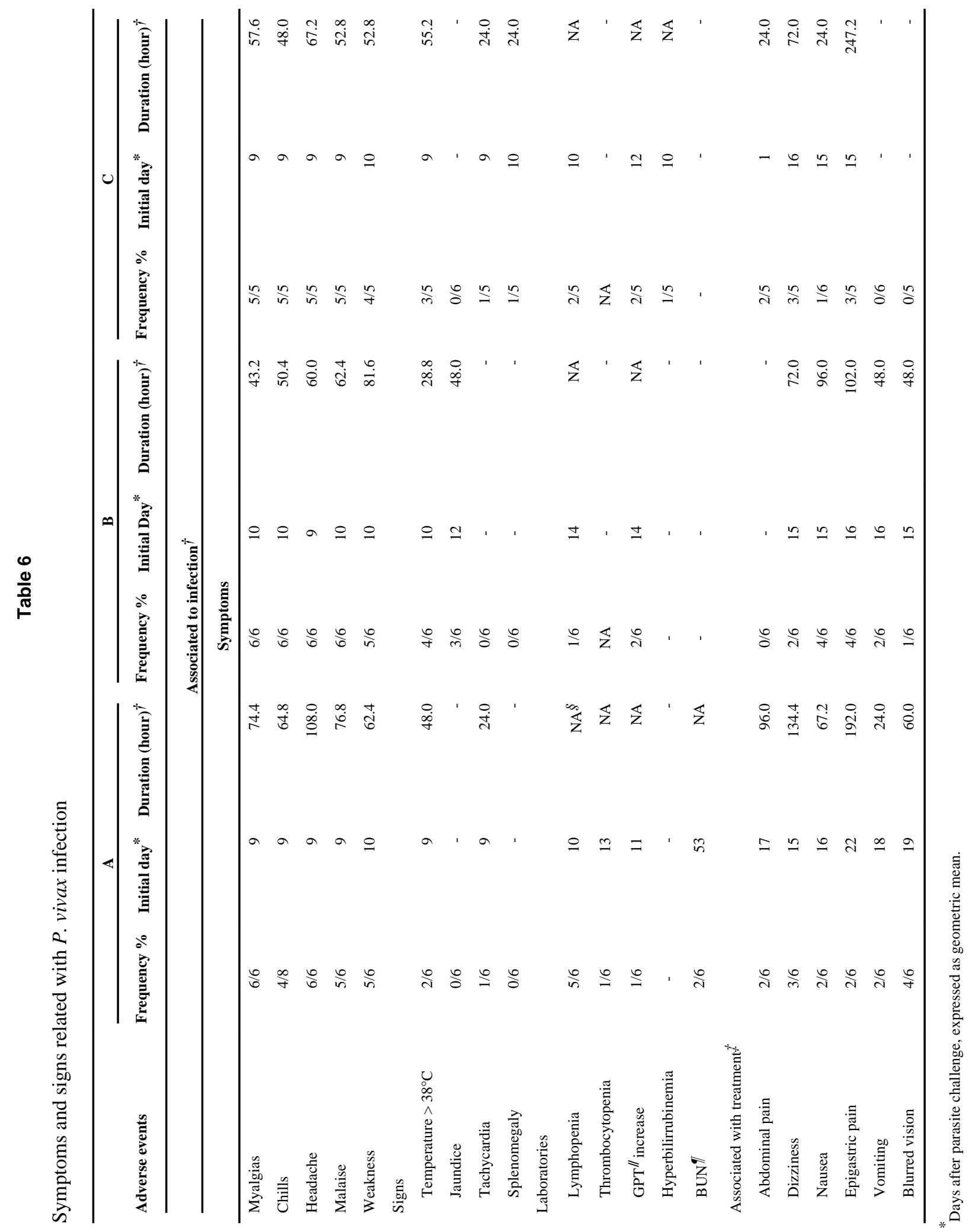


